\title{
EDITORIAL
}

\section{Magnesium and lymphoma: opportunities in translation}

Leukemia (2014) 28, 729-731; doi:10.1038/leu.2013.327

Observations in rare diseases may change therapeutic thinking in more common conditions. Chaigne-Delalande et al. ${ }^{1}$ showed in Science that in a recently discovered X-linked immune deficiency syndrome called XMEN disease, magnesium is a novel element in the pathogenesis of lymphoma. This finding and other supporting evidence may explain at least partially why people with diabetes mellitus, obesity or a transplant organ share an increased risk of both magnesium deficiency and lymphoma., ${ }^{2,3}$

\section{WHAT DID CHAIGNE-DELALANDE DISCOVER ABOUT X-MEN?}

In XMEN, a faulty cellular magnesium transporter (MAGT1) leads to a decrease in T-cell receptor-mediated magnesium influx, lowering intracellular free magnesium concentrations thereby impairing T-cell signaling and activation. ${ }^{4}$ At first, the investigators assumed this deregulated T-cell homeostasis would explain the increased risk of chronic viral infections such as Epstein-Barr virus (EBV) and of lymphoma. ${ }^{4}$ Now, we know that magnesium is also involved in the blunted cytolytic response against EBV. ${ }^{1}$ The decreased intracellular magnesium content in XMEN attenuates the expression of the natural killer (NK)-activating receptor NKG2D in both NK cells and cytotoxic $\mathrm{CD}^{+}{ }^{+}$T lymphocytes. ${ }^{1}$ As a lower expression of this immune activator decreases cytolysis upon ligation, this finally results in an increased number of EBV-infected B cells and decreased level of anti-tumoral immunity. ${ }^{1}$ More importantly, magnesium supplements in vivo restore intracellular free magnesium and dose-dependently increase NKG2D expression. ${ }^{1}$ This further leads to the recovery of $\mathrm{NK}$ cell and $\mathrm{CD} 8{ }^{+}$T-lymphocyte cytotoxicity and a decrease of EBV-infected cells. ${ }^{1}$ This seems relevant as high levels of EBV are correlated with early lymphoma development in XMEN. Of interest, also diabetic patients have less NKG2D-expressing NK cells than healthy controls. ${ }^{5}$ Especially, patients with uncontrolled hyperglycemia share both a more profound depression of NKG2D expression and a lower intracellular magnesium concentration than diabetic patients with good metabolic control. ${ }^{5}$ Hence, the basic findings in XMEN may be highly relevant for other clinical conditions, especially diabetes and posttransplant status.

\section{HOW COULD THESE FINDINGS CHANGE OUR CLINICAL PRACTICE?}

Intracellular (free) magnesium status increases the expression of NKG2D, which might contribute to NK cells becoming a central actor in the innate immunity against viral infections and cancer. We should bear in mind that clinical trials are needed to support the assertion that magnesium status is at play here. Magnesium supplementation, aimed at increasing intracellular free magnesium concentration, might restore cytotoxicity of NK cells and $\mathrm{CD}^{+}{ }^{+} \mathrm{T}$ lymphocytes in selected patients. Suitable patients are particularly those at risk of lymphoproliferative disease, like transplant recipients, especially with EBV-negative acceptor status.

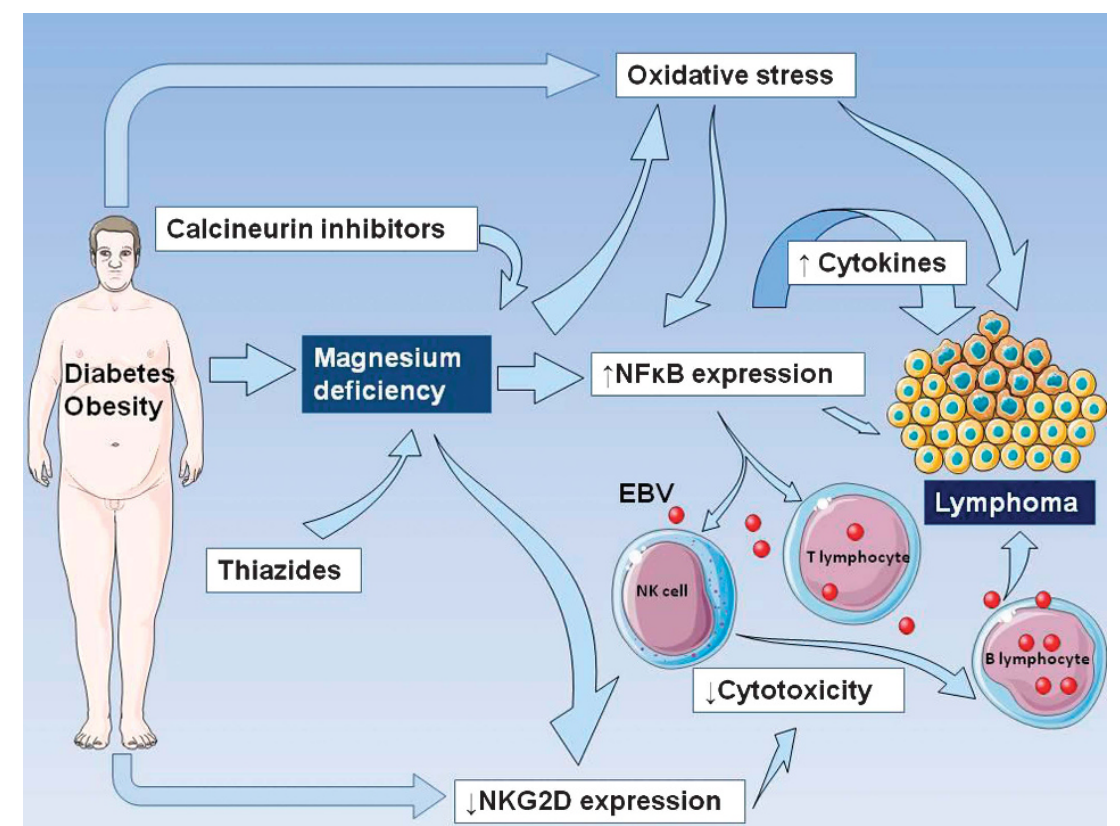

Figure 1. Magnesium deficiency and lymphoma. Simplified projection of how conditions associated with magnesium deficiency could predispose to the development of lymphoma. Proposed mechanisms by which hypomagnesemia might be stimulatory are induction of NF$\kappa B$, oxidative stress, increased cytokine production and decreased expression of NKG2D leading to decreased cytotoxicity of NK cells and T lymphocytes and an increase in EBV-positive B cells. 


\section{CLINICAL SUPPORT FOR A ROLE OF MAGNESIUM STATUS IN THE DEVELOPMENT OF LYMPHOMA}

The findings in XMEN indirectly suggest that a chronic magnesium deficiency may predispose to lymphoproliferative disease. They contribute to a mechanistic framework that associates magnesium deficiency and its related conditions with an increased risk of lymphoma (Figure 1).

In comparison with the general population, patients with diabetes more often have a shortage of extra- and intracellular magnesium. ${ }^{6}$ They also develop non-Hodgkin lymphoma (NHL) more frequently. ${ }^{2}$ Similarly, obese children without diabetes have lower serum and intracellular magnesium concentrations and develop NHL more often than lean children. ${ }^{7}$

Hydrochlorothiazides often lead to magnesium deficiency and its use was prevalent $(25 \%)$ at initial stage in a large cohort of patients with cutaneous T-cell lymphoma $(N=1443) .{ }^{8}$ Remarkably, up to $30 \%$ of patients on thiazides experienced complete or partial remission of their lymphoma after drug withdrawal. ${ }^{8}$ As some patients redeveloped cutaneous T-cell lymphoma after rechallenge, the role of thiazides as a putative antigen and its interaction with magnesium should be explored.

Following the introduction of calcineurin inhibitors (CNI), both extra- and intracellular magnesium deficiency became common after transplantation. ${ }^{9} \mathrm{CNI}$, especially tacrolimus, increase the risk of posttransplant lymphoproliferative disease (PTLD) versus recipients without $\mathrm{CNI}$ exposure. ${ }^{3} \mathrm{CNI}$ inhibit T-cell activation including that of EBV-specific $\mathrm{CD}^{+}{ }^{+} \mathrm{T}_{\text {cells. }}{ }^{10}$ In light of the findings by Chaigne-Delalande et al., magnesium deficiency and decreased expression of NKG2D are possibly at play here. Pediatric patients with PTLD had impaired NK function together with decreased NKG2D expression but data on magnesium status were unavailable. ${ }^{11}$

In the general population, low magnesium intake predicts the development of $\mathrm{NHL}^{12}$

About $60 \%$ of patients diagnosed with NHL are aged 65 years and above. Similarly, cytosolic free magnesium concentrations decrease linearly with increasing age.

In rats, a magnesium-deficient diet results in immunological alterations, thymus degeneration and lymphoma. ${ }^{13}$

\section{BASIC SUPPORT FOR A ROLE OF MAGNESIUM STATUS IN THE DEVELOPMENT OF LYMPHOMA}

In addition, magnesium has pleiotropic immunological effects in humans apart from decreased NK cell cytotoxicity. Magnesium deficiency upregulates proinflammatory cytokines and increases oxidative stress, which contribute to the development of NHL. ${ }^{14-16}$ It activates the redox-sensitive transcription factor nuclear factor kappa-B (NF- $\kappa$ B), whose constitutive activation is being recognized as critical in the pathogenesis of lymphoma and in the progression of EBV-induced malignancy. ${ }^{17,18} \mathrm{NF}-\kappa \mathrm{B}$ mediates various effects of viral infection that contribute to carcinogenesis such as antiapoptosis and stimulation of cellular proliferation. ${ }^{18}$ Likewise, magnesium dose-dependently attenuates the cytokine response of human monocytes to stimulation by Toll-like receptor ligands by decreasing the activation of NF- $\mathrm{KB}^{19}$

Other mechanisms by which magnesium might interfere with the development of lymphoma are more elusive or rather speculative. Magnesium is important for maintaining genomic stability. ${ }^{20}$ A magnesium deficit may inhibit DNA repair and lead to viable cell clones with unstable genomes. Magnesium is also a natural calcium antagonist. Of potential interest here, it might antagonize the modifications of calcium homeostasis induced by EBV and its oncoprotein LMP-1 (latent membrane protein-1) that contribute to the genesis of EBV-associated tumors. ${ }^{21}$ Upregulation of LMP-1 expression in stimulated B cell lines lead to an increased cytosolic calcium concentration, endoplasmic reticulum content and altered lymphopoiesis leading to tumorigenesis. ${ }^{21}$ Intracellular magnesium may oppose these processes. In T cells, MAGT1 deficiency abrogates transient rapid magnesium influx induced by antigen receptor stimulation, which leads to impaired calcium influx and decreased activation of these cells. ${ }^{4}$

There are many reasons to believe that magnesium deficiency may predispose to lymphoma irrespective of EBV status. There is also mounting evidence that magnesium deficits have a facilitating role in cancer. On the other hand, magnesium supplements may stimulate malignant lymphocytes to multiply. Magnesium has anti-apoptotic properties, is crucial for DNA replication and repair, is important for cell cycle progression and is important for protein synthesis. In mice, magnesium deficiency even slows primary tumor growth. ${ }^{20}$ Magnesium supplements may only be beneficial in the early stages of cancer, whereas in the later stages, they may actually be harmful.

To conclude, the recent findings by Chaigne-Delalande et al. substantiate the concept that magnesium deficiency is critically involved in the pathogenesis of lymphoma. The complexity of how this occurs sharply opposes the ostensible simplicity of its treatment approach. Yet in the absence of controlled trials, any treatment recommendation so far is preliminary and possibly invalid. At least, observations should create an impetus for therapeutic applications aiming at restoral of cytotoxicity and prevention of lymphoma by targeted magnesium supplementation. It remains unclear whether at a certain point in time this might not become harmful. This persisting ambiguity has puzzled oncologists for many years. It should, however, not deter researchers from further attempts to rigorously explore this paradigm, which could radically alter our therapeutic approach of lymphoma.

\section{CONFLICT OF INTEREST}

The authors declare no conflict of interest.

\section{AUTHOR CONTRIBUTIONS}

All authors contributed to drafting, writing and revising the paper.

S Van Laecke, EV Nagler and R Vanholder Renal Division, Ghent University Hospital, Ghent, Belgium E-mail: steven.vanlaecke@ugent.be

\section{REFERENCES}

1 Chaigne-Delalande B, Li F-Y, O'Connor GM, Lukacs MJ, Jiang P, Zheng $L$ et al. $\mathrm{Mg} 2+$ regulates cytotoxic functions of $\mathrm{NK}$ and $\mathrm{CD} 8 \mathrm{~T}$ cells in chronic EBV infection through NKG2D. Science 2013; 341: 186-191.

2 Tseng $\mathrm{CH}$. Diabetes and non-Hodgkin's lymphoma: analyses of prevalence and annual incidence in 2005 using the National Health Insurance database in Taiwan. Ann Oncol 2012; 23: 153-158.

3 van Leeuwen MT, Grulich AE, Webster AC, McCredie MR, Stewart JH, McDonald SP et al. Immunosuppression and other risk factors for early and late non-Hodgkin lymphoma after kidney transplantation. Blood 2009; 114: 630-637.

4 Li F-Y, Chaigne-Delalande B, Kanellopoulou C, Davis JC, Matthews HF, Douek DC et al. Second messenger role for $\mathrm{Mg} 2+$ revealed by human T-cell immunodeficiency. Nature 2011; 475: 471-476.

5 Berrou J, Fougeray S, Venot M, Chardiny V, Gautier J-F, Dulphy N et al. Natural killer cell function, an important target for infection and tumor protection, is impaired in type 2 diabetes. PLoS One 2013; 8: e62418.

6 Resnick LM, Altura BT, Gupta RK, Laragh JH, Alderman MH, Altura BM. Intracellular and extracellular magnesium depletion in type 2 (non-insulin-dependent) diabetes mellitus. Diabetologia 1993; 36: 767-770.

7 Bertrand KA, Giovannucci E, Zhang SM, Laden F, Rosner BA, Birmann BM. A prospective analysis of body size during childhood, adolescence, and adulthood and risk of non-Hodgkin lymphoma. Cancer Prev Res 2013; 6: 864-873.

8 Jahan-Tigh RR, Huen AO, Lee GL, Pozadzides JV, Liu P, Duvic M. Hydrochlorothiazide and cutaneous T cell lymphoma. Cancer 2013; 119: 825-831. 
9 Van Laecke S, Van Biesen W, Verbeke F, De Bacquer D, Peeters P, Vanholder R. Posttransplantation hypomagnesemia and its relation with immunosuppression as predictors of new-onset diabetes after transplantation. Am J Transplant 2009; 9: 2140-2149.

10 Burman K, Crawford DH. Effect of FK 506 on Epstein-Barr virus specific cytotoxic T cells. Lancet 1991; 337: 297-298.

11 Wiesmayr S, Webber SA, Macedo C, Popescu I, Smith L, Luce J et al. Decreased NKp46 and NKG2D and elevated PD-1 are associated with altered NK-cell function in pediatric transplant patients with PTLD. Eur J Immunol 2012; 42: 541-550.

12 Chiu BH, Kwon S, Evens A, Surawicz T, Smith S, Weisenburger D. Dietary intake of fruit and vegetables and risk of non-Hodgkin lymphoma. Cancer Causes Control 2011; 22: 1183-1195.

13 Averdunk R, Bippus PH, Gunther T, Merker HJ. Development and properties of malignant lymphoma induced by magnesium deficiency in rats. J Cancer Res Clin Oncol 1982; 104: 63-73.

14 Weglicki WB. Hypomagnesemia and inflammation: clinical and basic aspects. Annu Rev Nutr 2012; 32: 55-71.
15 Purdue MP, Lan Q, Bagni R, Hocking WG, Baris D, Reding DJ et al. Prediagnostic serum levels of cytokines and other immune markers and risk of non-Hodgkin lymphoma. Cancer Res 2011; 71: 4898-4907.

16 Imbesi S, Musolino C, Allegra A, Saija A, Morabito F, Calapai G et al. Oxidative stress in oncohematologic diseases: an update. Expert Rev Hematol 2013; 6: 317-325.

17 Jost PJ, Ruland J. Aberrant NF-KB signaling in lymphoma: mechanisms, consequences, and therapeutic implications. Blood 2007; 109: 2700-2707.

18 de Oliveira DE, Ballon G, Cesarman E. NF- $\mathrm{KB}$ signaling modulation by EBV and KSHV. Trends Microbiol 2010; 18: 248-257.

19 Sugimoto J, Romani AM, Valentin-Torres AM, Luciano AA, Ramirez Kitchen CM, Funderburg $\mathrm{N}$ et al. Magnesium decreases inflammatory cytokine production: a novel innate immunomodulatory mechanism. J Immunol 2012; 188: 6338-6346. 20 Anghileri LJ. Magnesium, calcium and cancer. Magnes Res 2009; 22: 247-255.

21 Dellis O, Arbabian A, Papp B, Rowe M, Joab I, Chomienne C. Epstein-Barr virus latent membrane protein 1 increases calcium influx through store-operated channels in B lymphoid cells. J Biol Chem 2011; 286: 18583-18592. 